\title{
Sizing chromosomes and megaplasmids in haloarchaea
}

\author{
P. López-García,† R. Amils and J. Antón \\ Author for correspondence: R. Amils. Tel: +341 3978078. Fax: +34 13978344.
}

Centro de Biología Molecular, Universidad Autónoma de Madrid, Cantoblanco, 28049 Madrid, Spain

\begin{abstract}
PFGE was used for the genomic analysis of different species and strains belonging to four out of the six recognized haloarchaeal (halobacterial) genera. All of them were found to carry one chromosome from 1.8-3 Mb, and usually several, but at least one, large plasmids of approximately $90-680 \mathrm{~kb}$, which were detected in supercoiled and linear forms. From the data gathered, chromosomal size appears to be conserved at genus level, whereas plasmid composition and size seems to be subjected to certain variability.
\end{abstract}

Keywords: megaplasmid, haloarchaea, chromosome, pulsed-field gel electrophoresis

\section{INTRODUCTION}

Extremely halophilic Archaea have been classified into six recognized genera (Halobacterium, Haloarcula, Haloferax, Halococcus, Natronobacterium and Natronococcus) (Juez, 1989) to which two new genera, Halorubrum and Natrialba, have been added recently (Kamekura \& Dyall-Smith, 1995). Genetic and genomic studies have been carried out mainly with Halobacterium and Haloferax species (Doolittle, 1985; Pfeiffer, 1988; Schalkwyk, 1993). The complete genomic maps of Haloferax volcanii, Halobacterium sp. GRB and Halobacterium salinarum have been reported (Charlebois et al., 1991; Saint Jean et al., 1994; Bobovnikova et al., 1994), as well as the chromosomal physical map of Haloferax mediterranei (López-García et al., 1992; Antón et al., 1994). In both Haloferax species the genome is composed of a circular chromosome of approximately $2.9 \mathrm{Mb}$, and three large extrachromosomal elements ranging in size from 86 to $690 \mathrm{~kb}$. Hf. volcanii also carries an additional small plasmid $(6.35 \mathrm{~kb})$. In Halobacterium sp. GRB the genome also consists of several replicons, the chromosome $(2 \cdot 038 \mathrm{Mb})$ and four plasmids $(305,90,37$ and $1.8 \mathrm{~kb})$, as is the case for $\mathrm{Hb}$. salinarum NRC1 carrying one chromosome and two megaplasmids (Bobovnikova et al., 1994).

The existence of megaplasmids in haloarchaea has been reported previously (Gutiérrez et al., 1986) and an early attempt to estimate their sizes was carried out using classical electrophoretic analysis in spite of the inability of this technique to achieve accurate resolution of large

†Present address: Institut de Génetique et Microbiologie, Centre National de la Reserche Scientifique, Université Paris-Sud, 91405 Orsay Cedex, France.

$\ddagger$ Present address: Departamento de Genética y Microbiología, Campus de San Juan, Universidad de Alicante, Apdo. 374, 03080 Alicante, Spain.
DNAs. Using PFGE, which allows the resolution of large DNA molecules, in either linear or supercoiled form (Smith et al., 1988; López-García et al., 1994), we have analysed the whole genomes of several species and strains of four haloarchaeal genera to detect the number of replicons present as well as their approximate sizes.

The objective of this work is to present new data and compare them with what is known about halobacterial genomic architecture. To date no general and systematic study regarding the genomic characteristics that are shared by the haloarchaea as a group has been performed.

\section{METHODS}

Organisms and growth conditions. The haloarchaeal species and strains used in this study are listed in Table 1 . They are representatives of four non-alkaliphilic genera (Halobacterium, Halorubrum, Haloarcula and Haloferax) and the alkaliphilic genus Natronobacterium. Halobacterium salinarum (formerly balobium) CCM 2090 was obtained from two different sources (Dr A. Ventosa, University of Sevilla, Spain, and Dr M. Kohiyama, Institut Jacques Monod, France). Natronobacterium pharaonis was grown in the specific medium of Tindall (1991). Other strains were grown in SW $25 \%$ supplemented with $0.5 \%$ yeast extract at $37{ }^{\circ} \mathrm{C}$ (Rodríguez-Valera et al., 1983) until late exponential phase, and then harvested by centrifugation at low speed.

DNA extraction. Intact genomic DNA was prepared as previously described (López-García et al., 1992; Smith et al., 1988).

PFGE. Orthogonal-field alternating gel electrophoresis (OFAGE) (Schwartz \& Cantor, 1984) and contour-clamped homogeneous electric field electrophoresis (CHEF) (Chu et al., 1984) were performed using a Pharmacia LKB Pulsaphor system. Some OFAGE gels were run using a $55 \times 55 \mathrm{~cm}$ homemade system (López-García et al., 1994). $\lambda$ DNA concatemers (Pharmacia) and chromosomes of Saccharomyces cerevisiae YN295 and Schizosaccharomyces pombe DSM 70576 were used as linear size standards. 
Hybridization. For the hybridization experiment, DNA was transferred onto a Nylon membrane as described by Smith et al. (1988). The megaplasmids used as probes were purified from PFGE gels, digoxigenin (DIG)-labelled directly in agarose by random primed synthesis and hybridized as described by the manufacturers (DIG-System, Boehringer Mannheim).

\section{RESULTS AND DISCUSSION}

\section{Chromosomal size}

Although circular chromosomes are unable to enter pulsed field gels due to their large sizes (Smith \& Condemine, 1990), when intact DNA preparations are subjected to PFGE using high pulse times, and low electrical fields for long running times, some chromosomes randomly linearized by mechanical stress can be fractionated (López-García et al., 1992). In this manner, the linearized chromosomes of three representative species of the genus Haloferax, two of Haloarcula, two of Halobacterium (including three different strains of $\mathrm{Hb}$. salinarum) and one of Natronobacterium (not shown) were resolved by PFGE (Fig. 1). Only a small proportion of total DNA was linearized and most of the chromosome remained in the well (compared with the intensity of the ethidium bromide staining of the fractionated chromosome). Their approximate sizes (Table 1) were calculated by comparison with linear DNA molecules of known sizes.

In the analysed genomes, chromosomal sizes from species belonging to the same genus are similar. Thus, the three Haloferax species harbour a chromosome of approximately $2.9 \mathrm{Mb}$. This size has been further confirmed by physical mapping in the cases of $H f$. volcanii and $H f$. mediterranei (Charlebois et al., 1991; López-García et al., 1992). Both Haloarcula species carry a chromosome of

Table 1. Number and approximate sizes of genomic replicons in haloarchaea

\begin{tabular}{|c|c|c|c|}
\hline \multirow[t]{2}{*}{ Haloarchaeal species } & \multirow{2}{*}{$\begin{array}{l}\text { Chromosomal } \\
\text { size }(\mathbf{M b})\end{array}$} & \multicolumn{2}{|c|}{ Extrachromosomal elements } \\
\hline & & $\begin{array}{l}\text { Approximate } \\
\text { size (kb) }\end{array}$ & Number \\
\hline Halobacterium salinarum (balobium) NRC 817 & $1 \cdot 8$ & $\begin{array}{c}160 \\
130 \\
\text { Small }(<50)\end{array}$ & 3 \\
\hline Halobacterium salinarum (balobium) CCM 2090* & $1 \cdot 8$ & $\begin{array}{r}350 \\
160 \\
70\end{array}$ & 3 \\
\hline Halobacterium salinarum (balobium) CCM $2090 \dagger$ & $1 \cdot 8$ & $\begin{array}{l}300 \\
120\end{array}$ & 2 \\
\hline Halobacterium salinarum (balobium) CECT 396 & $1 \cdot 8$ & $\begin{array}{r}250 \\
160 \\
70\end{array}$ & 3 \\
\hline Halorubrum sodomense ATCC 33755 & 2 & $\begin{array}{r}100 \\
70\end{array}$ & 2 \\
\hline Haloarcula bispanica ATCC 33960 & 3 & $\begin{array}{l}400 \\
370 \\
130\end{array}$ & 3 \\
\hline Haloarcula vallismortis ATCC 29715 & 3 & $\begin{array}{l}400 \\
280 \\
140 \\
130\end{array}$ & 4 \\
\hline Haloferax mediterranei ATCC 33500 & $2 \cdot 9$ & $\begin{array}{l}495 \\
320 \\
130\end{array}$ & 3 \\
\hline Haloferax volcanii NCMB 2012 & $2 \cdot 9$ & $\begin{array}{r}680 \\
410 \\
90 \\
6\end{array}$ & 4 \\
\hline Haloferax gibbonsii ATCC 33959 & $2 \cdot 9$ & $\begin{array}{l}430 \\
350 \\
150\end{array}$ & 3 \\
\hline Natronobacterium pharaonis ATCC 35678 & 2 & 130 & 1 \\
\hline
\end{tabular}

* Strain obtained from Dr A. Ventosa, Sevilla, Spain.

† Strain obtained from Dr M. Kohiyama, Paris, France. 

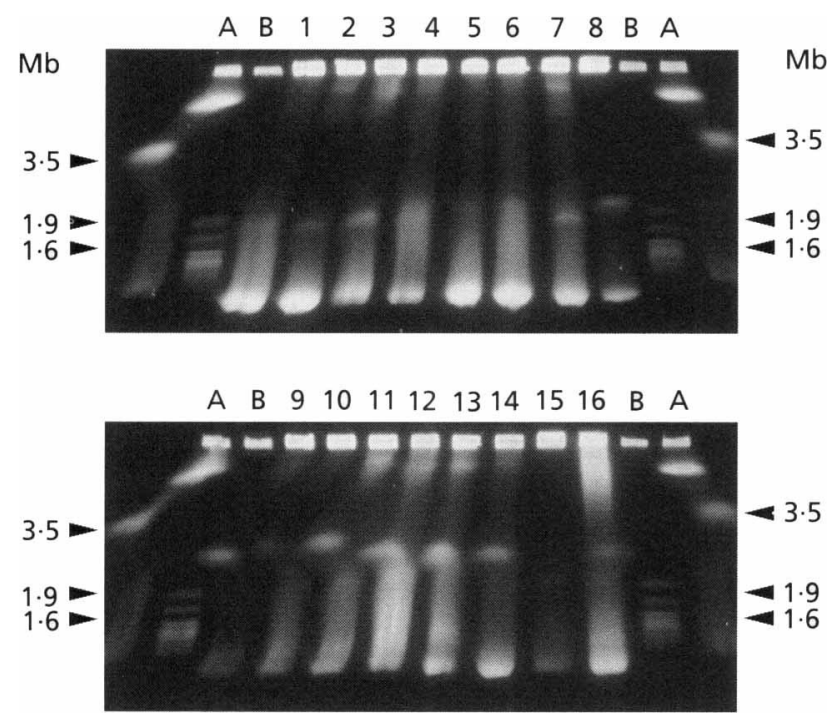

Fig. 1. Linearized chromosomes of different haloarchaea. DNA was fractionated by PFGE using a pulse time of $2000 \mathrm{~s}$ at $3.3 \mathrm{~V} \mathrm{~cm}^{-1}$ for $120 \mathrm{~h}$. Lanes: $1, \mathrm{Hb}$. salinarum NRC 817; 2, Spanish $H b$. salinarum CCM 2090 (see Table 1); 3, French $H b$. salinarum CCM 2090 (Table 1); 4, Hb. salinarum CECT 396; 5 $\mathrm{Hb}$. salinarum (formerly $\mathrm{Hb}$. cutirubrum) CCM 2688; 6, Hb. salinarum NRC 34002; 7, Halobacterium sp.; 8, Hr. (formerly Hb.) sodomense ATCC 33755; 9, Ha. hispanica ATCC 33960; 10, Ha. vallismortis ATCC 29715; 11, Ha. vallismortis (marismortui); 12, Hf. mediterranei ATCC 33500; 13, Hf. volcanii NCMB 2012; 14, Hf. gibbonsii ATCC 33959; 15, Hc. morrhuae CCM 537; 16, a natural halophilic isolate from La Mancha, Spain. Chromosomes of Schiz. pombe (A) and Sacch. cerevisiae (B) were used as linear size standards.

approximately $3 \mathrm{Mb}$, slightly larger than those from the Haloferax group. Finally, all the strains of $\mathrm{Hb}$. salinarum tested carry a chromosome of similar size, around $1.8 \mathrm{Mb}$, which is smaller than the chromosome of Halorubrum sodomense (approximately $2 \mathrm{Mb}$ ), which for years has been classified into the genus Halobacterium. In this latter case, the difference in chromosomal size adds genomic evidence to the distinct nature of this species, which had been found to constitute a separate cluster by numerical taxonomy studies and polar lipid composition, and predicted to represent a new genus (Torreblanca et al., 1986; Trincone et al., 1990).

So far, more than 50 prokaryotic chromosomes have been physically mapped, nearly 10 of which belong to the archaeal domain. In spite of having greater similarities with eukaryotes, mostly at the protein level (Cole \& Saint Girons, 1994), the chromosome and, in general, archaeal genome organization appears to be bacteria-like. Moreover, haloarchaeal chromosomes are not extreme in size when compared to other prokaryotes.

Although comparative genomics of prokaryotes is a new discipline, the first comparisons of chromosomal sizes and physical and genetic maps are producing useful information at both phylogenetic and structure/function levels. In this sense, knowledge of the sizes of haloarchaeal chromosomes and of their degree of conservation at taxonomic levels constitutes an initial step, prior to physical and genetic mapping, in the exploration of the comparative genomics of this group.

\section{Large extrachromosomal elements}

Large haloarchaeal plasmids can be separated by PFGE in supercoiled (SC) or linear (L) forms, while open circular molecules either remain trapped in wells (if they are too large) or migrate short distances without being resolved (López-García et al., 1994). PFGE of intact DNA from the haloarchaea used in this study (Table 1) revealed the presence of large plasmids, which were detected either in $\mathrm{SC}, \mathrm{L}$ (as a consequence of random breakage) or both forms (Fig. 2).

Since supercoiled forms of large plasmids migrate with a certain dependence on the pulse time applied, but in a sizeindependent manner (López-García et al., 1994), they usually migrate less than the linear molecules, and remain in the upper part of the gel. For haloarchaeal megaplasmids ranging between 100 and $600 \mathrm{~kb}$, the best resolution of supercoiled molecules was achieved with pulses ranging from 50 to $200 \mathrm{~s}$, although they could also be observed when longer pulses were used to separate Mb-sized linear molecules (Fig. 1). The largest megaplasmids linearize easily under mechanical stress and are, therefore, difficult to observe in the supercoiled form. This phenomenon is illustrated in Fig. 3. Fig. 3(a) shows a PFGE gel of different $H f$. mediterranei genomic DNA

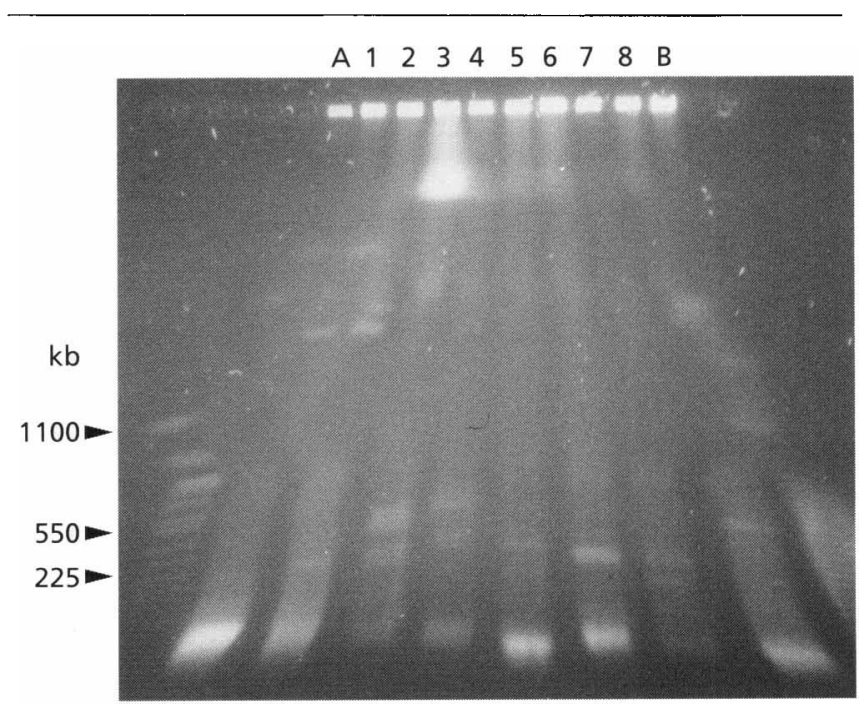

Fig. 2. Resolution of large haloarchaeal plasmids by OFAGE using a pulse time of $100 \mathrm{~s}$ at $10 \mathrm{~V} \mathrm{~cm}^{-1}$ for $24 \mathrm{~h}$ and a pulse time of $300 \mathrm{~s}$ at $8 \mathrm{~V} \mathrm{~cm}^{-1}$ for $24 \mathrm{~h}$. Lanes: 1, Spanish $\mathrm{Hb}$. salinarum CCM 2090; 2, French Hb. salinarum CCM 2090; 3, Hf. mediterranei ATCC 33500; 4, Hf. volcanii NCMB 2012; 5 , Hf. gibbonsii ATCC 33959; 6, Ha. hispanica ATCC 33960; 7, Ha. vallismortis ATCC $29715 ; 8$, a natural halophilic isolate from la Mancha, Spain. Chromosomes of Sacch. cerevisiae (A) and $\lambda$ concatamers from Pharmacia (B) were used as linear size standards. 
(a)

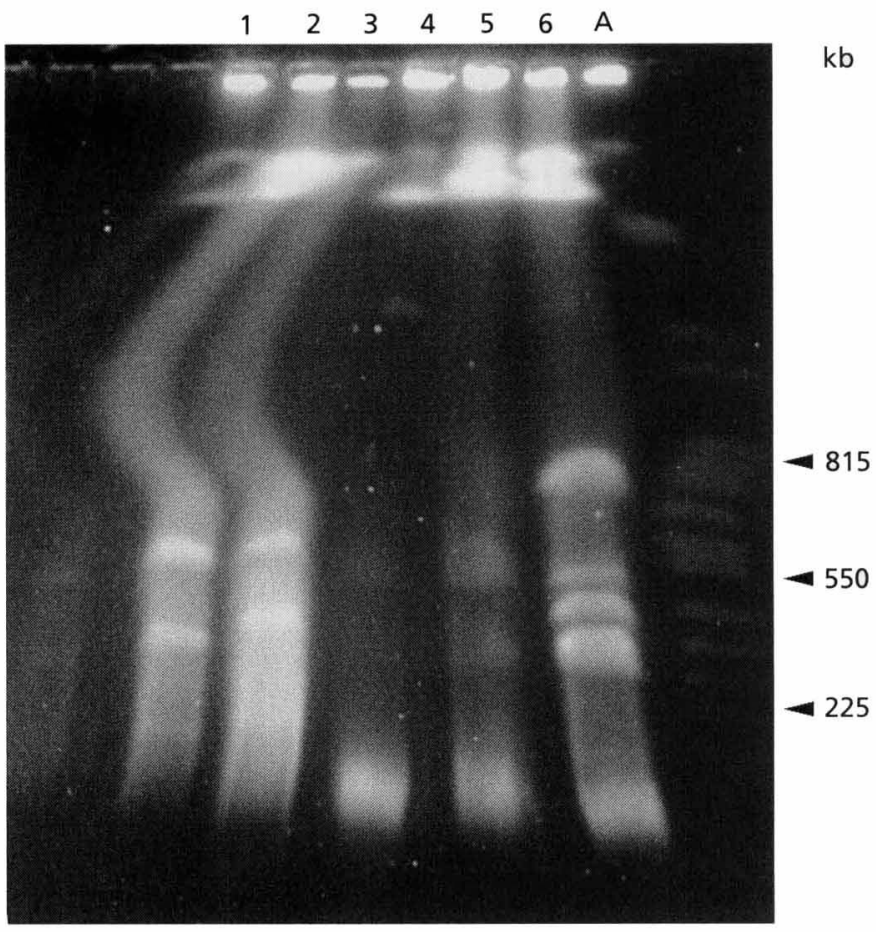

(b)

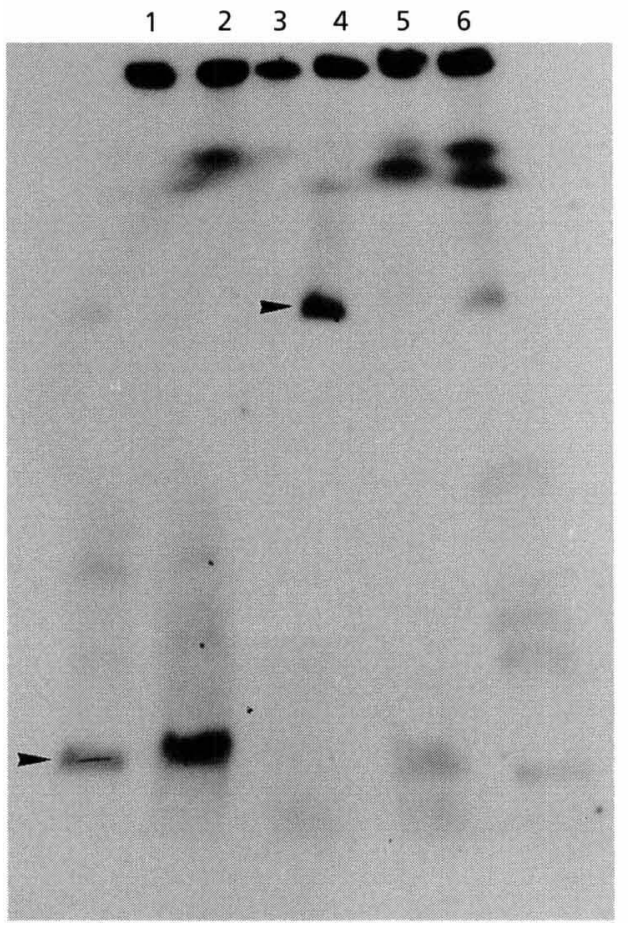

(c)

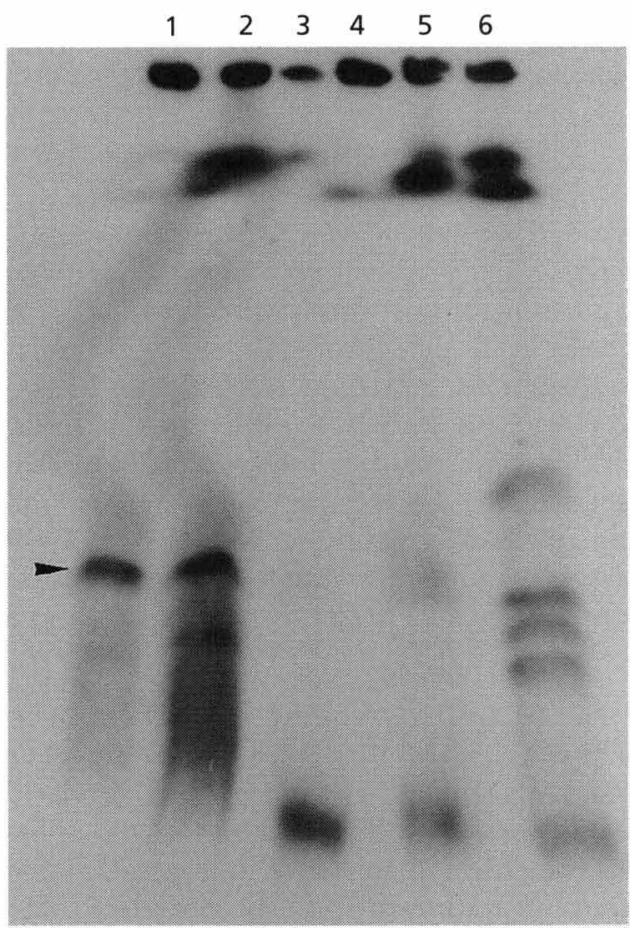

Fig. 3. Resolution of Hf. mediterranei megaplasmids. Two sets of total DNA samples $(1,2$ and 3 , pre-run with a pulse time of $150 \mathrm{~s}$ at $10 \mathrm{~V} \mathrm{~cm}^{-1}$ for $40 \mathrm{~h} ; 4,5$ and 6 , not pre-run) were fractionated by OFAGE using a pulse time of $100 \mathrm{~s}$ at $10 \mathrm{~V} \mathrm{~cm}{ }^{-1}$ for $42 \mathrm{~h}$ (a). Samples 1 and 4 were run without previous treatment; 2 and 5 were incubated in restriction buffer at $37^{\circ} \mathrm{C}$ overnight; 3 and 6 were digested with the macrorestriction enzyme Pacl. After Southern blotting, the gel was hybridized with DIG-labelled pHM100 (b) and DIG-labelled pHM500 (c). Sacch. cerevisiae chromosomes were used as size standards (A). 
samples (see legend). Samples 1, 2 and 3 had been pre-run and, therefore, exposed to shear damage. After Southern blotting, the gel was hybridized with pHM100 $(130 \mathrm{~kb})$ and pHM500 (495 kb), two of the three megaplasmids present in this haloarchaeon. When hybridized with pHM100 (Fig. 3b), this element could be detected in the genomic DNA in two forms: linear (arrow in lanes 2 and 3 ) and supercoiled (lane 4). However, when pHM500 was used as probe (Fig. 3c), only the linear form could be observed. Megaplasmids can be detected either in linear or both linear and supercoiled forms according to their sizes and, therefore, their susceptibility to shear stress and nuclease activity.

For approximate sizing, $\mathrm{L}$ forms, whose migration is sizeand pulse-time-dependent, were fractionated by PFGE undet the appropriate conditions for resolution in each case and compared with linear size standards (Fig. 2 shows an example). The number and approximate size of the extrachromosomal elements detected are given in Table 1 . The most notable conclusion of this study is that all the haloarchaea tested contained megaplasmids. The presence of these elements can account for up to $30 \%$ of the genome size. As mentioned above, the occurrence of megaplasmids in haloarchaea has been reported previously (Gutiérrez et al., 1986). Although some good estimates were given (Gutiérrez et al., 1986), others differ greatly from the values we present here, which are more reliable since they have been obtained using a much more appropriate technology; in addition, some large megaplasmids were not detected at all or even, in the case of $H f$. gibbonsii, no plasmids were found, revealing that this early approach, although useful, had limitations.

Although the chromosomal size seems to be well conserved in a given genus, plasmid sizes and composition may vary not only among different strains from the same species, as is the case for Hb. salinarum or Hf. mediterranei (López-García et al., 1993), but also in the same strain, as occurs in Hb. salinarum CCM 2090 which was obtained from two different sources. Therefore, genome variability seems to be maintained at extrachromosomal levels, where insertion sequences families are most abundant (Doolittle, 1985; Pfeiffer, 1988) and the rearrangements they mediate may take place readily.

The presence of megaplasmids has been reported in different kinds of bacteria (Krawiec \& Riley, 1990). Particularly, many specialized metabolic or interactive capabilities of bacteria depend on genes contained in megaplasmids, such as Rbizobium symbiosis (Johnston, 1989), Agrobacterium tumour induction (Hooykaas, 1989), Streptomyces antibiotic biosynthesis (Kinashi et al., 1992) and Pseudomonas organic compound degradation (Frantz \& Chakrabarty, 1986). However, little is known about the genes on halobacterial megaplasmids. Among the genes mapped in Hf. mediterranei (López-García et al., 1992; Antón et al., 1994) and Hf. volcanii (Cohen et al., 1992) none have been found to present a copy only in megaplasmids, since all the genes mapped in these replicons have at least one homologous copy in the main chromosome. The megaplasmid pHH1 $(150 \mathrm{~kb})$ and the related pNRC100 $(200 \mathrm{~kb})$ from two distinct $H$ b. salinarum strains carry the genes for synthesis of buoyant gas-filled vesicles (Ng et al., 1991; Horne et al., 1991). Apparently copies of these genes were also found in the chromosome (Horne et al., 1988). In Halobacterium sp. GRB, gas vesicle genes map only in the megaplasmid pGRB305 (Saint Jean et al., 1994).

The advantage that bacteria might have from segregating their genetic material into several units has been explained on the basis of a mathematical model for the description of the growth of individual microbial cells (Stouthamer \& Kooijman, 1993). The essential features of the model are that the uptake of nutrients is proportional to the surface area of the cell and maintenance costs are proportional to the volume. Growth of the individual cell continues until DNA replication of the genome is completed. The consequence is that cells with large genome size are bigger at the moment of cell division. In cells in which the total DNA is divided over several units which replicate simultaneously (e.g. a cell with more chromosomes or a cell with one chromosome and one or more megaplasmids) a high surface to volume ratio can be maintained, which has a positive influence on the population growth rate.

According to this model, the presence of megaplasmids should be more generalized than is so far known. Therefore, other parameters are probably important for the determination of this kind of distribution into distinct large genomic units. The haloarchaeal case appears remarkable: all of the studied species present a high fraction of their genomes as large extrachromosomal elements or megaplasmids. What is the biological meaning of this genome partition? The identification of the genes present in megaplasmids could shed some light on this problem. But for now it remains an open question.

\section{ACKNOWLEDGEMENTS}

This work was supported by the Ramón Areces Foundation and the Spanish Interministerial Commission for Science and Technology (CICYT) grant no. PB92-0129.

\section{REFERENCES}

Antón, J., López-García, P., Abad, J. P., Smith, C. L. \& Amils, R. (1994). Alignment of genes and $S w a I$ restriction sites to the BamHI genomic map of Haloferax mediterranei. FEMS Microbiol Lett 117, 53-60.

Bobovnikova, Y., Ng, W. L., DasSarma, S. \& Hackett, N. R. (1994). Restriction mapping the genome of Halobacterium balobium strain NRC-1. Syst Appl Microbiol 16, 597-604.

Charlebois, R. L., Schalkwyk, L. C., Hofman, J. D. \& Doolittle, W. F. (1991). Detailed physical map and set of overlapping clones covering the genome of the archaebacterium Haloferax volcanii DS2. $J$ Mol Biol 222, 509-524.

Chu, G., Vollrath, D. \& Davies, R. W. (1984). Separation of large DNA molecules by contour-clamped homogeneous electric fields. Science 234, 1582-1585. 
Cohen, A., Lam, W. L., Charlebois, R., Doolittle, W. F. \& Schalkwyk, L. C. (1992). Localizing genes on the map of the genome of Haloferax volcanii, one of the Archaea. Proc Natl Acad Sci US $A$ 89, 1602-1606.

Cole, S. T. \& Saint Girons, I. (1994). Bacterial genomics. FEMS Microbiol Rev 14, 139-160.

Doolittle, W. F. (1985). Genome structure in archaebacteria. In The Bacteria, Vol. VIII, pp. 545-560. Edited by C. R. Woese \& R. S. Wolfe. London: Academic Press.

Frantz, B. \& Chakrabarty, A. M. (1986). Degradative plasmid in Pseudomonas. In The Bacteria, Vol. X: The Biology of the Pseudomonads, pp. 295-323. Edited by J. R. Sokatch. New York: Academic Press.

Gutiérrez, M. C., Garcla, M. T., Ventosa, A., Nieto, J. J. \& RulzBerraquero, F. (1986). Occurrence of megaplasmids in halobacteria. $J$ Appl Bacteriol 61, 67-71.

Hooykaas, P. J. J. (1989). Tumorigenicity of Agrobacterium on plants. In Genetics of Bacterial Diversity, pp. 373-391. Edited by D. A. Hopwood \& K. F. Chater. London: Academic Press.

Horne, M., Englert, C. \& Pfeiffer, F. (1989). Two genes encoding gas vacuole proteins in Halobacterium balobium. Mol Gen Genet 213, 459-464.

Horne, M., Englert, C., Wimmer, C. \& Pfeiffer, F. (1991). A DNA region of $9 \mathrm{~kb}$ contains all genes necessary for gas vesicle synthesis in halophilic halobacteria. Mol Microbiol 5, 1159-1174.

Johnston, A. W. B. (1989). The symbiosis between Rbizobium and legumes. In Genetics of Bacterial Diversity, pp. 393-438. Edited by D. A. Hopwood \& K. F. Chater. London: Academic Press.

Juez, G. (1988). Taxonomy of extremely halophilic archaebacteria. In Halophilic Bacteria, Vol. II, pp. 3-24. Edited by F. RodríguezValera. Boca Raton, Florida: CRC Press.

Kamekura, M. \& Dyall-Smith, M. L. (1995). Taxonomy of the family Halobacteriaceae and the description of two new genera Halorubrobacterium and Natrialba. J Gen Appl Microbiol 41, 333-350.

Kinashi, H., Shimaji-Murayama, M. \& Hanafusa, T. (1992). Integration of SCP1, a giant linear plasmid, into the Streptomyces coelicolor chromosome. Gene 115, 35-42.

Krawiec, S. \& Riley, M. (1990). Organization of the bacterial chromosome. Microbiol Rev 54, 502-539.

López-García, P., Abad, J. P., Smith, C. L. \& Amils, R. (1992). Genomic organization of the halophilic archaeon Haloferax mediterranei: physical map of the chromosome. Nucleic Acids Res 20, 2459-2464.

López-Garcla, P., Abad, J. P. \& Amils, R. (1993). Genome analysis of different Haloferax mediterranei strains using pulsed-field gel electrophoresis. Syst Appl Microbiol 16, 310-321.
López-García, P., Antón, J., Abad, J. P. \& Amils, R. (1994). Halobacterial megaplasmids are negatively supercoiled. $\mathrm{Mol}$ Microbiol 11, 421-427.

Ng, W. L., Kothakota, S. \& DasSarma, S. (1991). Structure of the gas vesicle plasmid in Halobacterium halobium: inversion isomers, inverted repeats, and insertion sequences. $J$ Bacteriol 173, 19581964.

Pfeiffer, F. (1988). Genetics of halobacteria. In Halophilic Bacteria, Vol. II, pp. 105-133. Edited by F. Rodríguez-Valera. Boca Raton, Florida: CRC Press.

Rodríguez-Valera, F., Juez, G. \& Kushner, D. J. (1983). Halobacterium mediterranei $\mathrm{sp}$. nov., a new carbohydrate-utilizing extreme halophile. Syst Appl Microbiol 4, 369-381.

Saint Jean, A., Trieselmann, B. A. \& Charlebois, R. L. (1994). Physical map and set of overlapping cosmid clones representing the genome of the archaeon Halobacterium sp. GRB. Nucleic Acids Res 22, 1476-1483.

Schalkwyk, L. C. (1993). Halobacterial genes and genomes. In The Biochemistry of Archaea (Archaebacteria), pp. 467-496. Edited by M. Kates, D. J. Kushner \& A. T. Matheson. Amsterdam: Elsevier.

Schwartz, D. C. \& Cantor, C. R. (1984). Separation of yeast chromosome-sized DNAs by pulsed field gel electrophoresis. Cell $37,67-75$.

Smith, C. L. \& Condemine, G. (1990). New approaches for physical mapping of small genomes. J Bacteriol 172, 1167-1172.

Smith, C. L., KIco, S. R. \& Cantor, C. R. (1988). Pulsed-field gel electrophoresis and the technology of large DNA molecules. In Genome Analysis: A Practical Approach, pp. 41-72. Edited by K. Davies. Oxford: IRL Press.

Stouthamer, A. H. \& Kooijman, S. A. L. M. (1993). Why it pays for bacteria to delete disused DNA and to maintain megaplasmids. Antonie Leeunenboek 63, 39-43.

Tindall, B. J. (1991). Cultivation and preservation of members of the family Halobacteriaceae. World J Microbiol Biotecbnol 7, 95-98.

Torreblanca, M., Rodriguez-Valera, F., Juez, G., Ventosa, A., Kamekura, M. \& Kates, M. (1986). Classification of non-alkaliphilic halobacteria based on numerical taxonomy and polar lipids pattern and description of Haloarcula gen. nov. and Haloferax gen. nov. Syst Appl Microbiol 8, 89-99.

Trincone, A., Nicolaus, B., Lama, L., De Rosa, M., Gambacorta, A. \& Grant, W. D. (1990). The glycolipid of Halobacterium sodomense. J Gen Microbiol 136, 2327-2331.

Received 3 January 1996; accepted 17 January 1996. 